\title{
Studies on the Pelagic Copepoda from the Japan Sea-II. On the Genus of Pontellopsis Brady 1883
}

\author{
Takuo CHIBA \\ (Shimonoseki College of Fishies)
}

\section{Introduction}

In the neighbouring water of Japan, Pontellopsis armata, $P$. perspicax, $P, y a-$ madae, $P$. tenuicauda were reported by T. Mori 1937. Reserching the planktons in the Japan Sea, 1 have discovered the new species, Pontellopsis pacifica sp. nov.

\section{Pontellopsis pacifica sp. nov.}

Occurrence. 7 females and 4 ma'es were caught on 10 May and 13 June 1951. lat. $34^{\circ} 24^{\prime} \mathrm{N}$. Long. $131^{\circ}, 10^{\prime} \mathrm{E}$.

Description. Fema ${ }^{1}$ e (Fig. 1), length 2.58-3.15 mm. This new species resembles to Pontellopsis laminata, P. yamadae, but is different on the following points. Its head round and broad in front, with a small projection over the base of rostrum. The lateral angels of the last thoracic segment are produced into blunty rounded process. The proportional length of the cephalothorax and the abdomen is as 150 to 65 , so the length of the cephalothorax is 2.72 times in that of the abdomen. The abdomen consists of 2 segments. The abdominal segments and the furca have the following proportional length;

$$
\text { Segment } \frac{12 \cdot f}{652015}=100
$$

The anterior antennae are 16 segmented, reaching only to the 4 th thoracic segment. The proportional length of the various segment have the following length:

$\begin{array}{rrrrrrrrrrrrrrrr}1 & 2 & 3 & 4 & 5 & 6 & 7 & 8 & 9 & 10 & 11 & 12 & 13 & 14 & 15 & 16 \\ -.34 & 100 & 34 & 82 & 57 & 34 & 24 & 55 & 57 & 74 & 90 & 65 & 65 & 82 & 65 & 8 ?\end{array}=1000$

The exopodite of the 2nd antenna is only one-4th as long as the endopodite and have 5 terminal setae. The exopodite of the first pairs of feet are 3-segmented, and the endopods of the first legs are 3 segmented, and the other 2-segmented. Genital segment with 2 short processes at the posterior of the ventral surface curves backward.

Received December 10, 1951.

Contribution Nr. 54 from Shimonoseki College of Eisheries. 
Laminae attaches to the dorsal surface of the segment at the posterior corner. These laminae are chitinous and parfectiy transparent, but of cource they are very b.ittle and likely to bə broken off. But this laminae remains unbroken. This new species, as Pontellopsis yamadae have not a pair of small spines on the proximal and also have not a flap on the distal position of the dorsal surface of the genital segment. The anal segment is short and inverginate posteriorly. The furca and the 5th pair of feet are nearly symmetrical. The endopodite are 1-segmented, and tcrminal segment ends into the bifurcate. The exopodite have outer marginal spines. The right exopodite has 2 stout inner marginal spines. The exopodite is about 3 times as long as the endopodite and its distal half is bifurcated, and the branch is blunt.

Male (Fig.2) length 2.16-2.34 mm. On the left cornor is a short and blunt process while on the right is a long sickle-shaped spine reaching to the middle sth abdominal segment but the latter dont reaches to the end of the anal segment. The endspine of the right process ends in acuminate point. The proportional length of the cephalothorax and the abdomen is as 140 to 40 , so the length of the cephalothorax is 3.5 times in that of the abdomen. The abdomen consists of 5 serments. The 3 rd segment have a knob on the right side. The abdomen segments and the furca have the following proportional length:

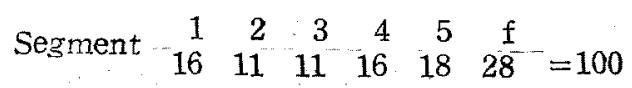

The right anterior antenna almost consists of $i 3$ segments and modified into the grasping organ. As can be sean in Figure 2, the basal segment is considerably wide and the ones next to the swollen knob are narrowed. The knob is abruptly widened, and its distal segment is toothed on the inner margin. The segment next to the hinge has a row of small teeth along its inner margin. The terminal section consists of 2 segments. The left antenna consists of i7 segments. The various segments of the left antenna have following length:

$$
\begin{array}{rrrrrrrrrrrrrrrrr}
1 & 2 & 3 & 4 & 5 & 6 & 7 & 8 & 9 & 10 & 11 & 12 & 13 & 14 & 15 & 16 & 17 \\
\hline 31 & 116 & 77 & 92 & 23 & 31 & 38 & 46 & 56 & 62 & 62 & 62 & 62 & 62 & 80 & 62 & 62
\end{array}=1000
$$

The terminal setae of the exopodite of the 2nd antenna has $6+7$ long haires. The 5th pairs of feet is asymmetrical. The right foot consists of a forcaps. The thumb reaches to the end of the terminal claw.

The left foot has 2 szyment. Exopodite ends in 2 short and endopodite has a short haired spine. The length of the endopodite of the left foot is as half as that of the exopodite. The furca is almost symmetrical and has many haires at inner margin. Two endospines among the furcal setae are longer than the other and are as long as the abdomen. 


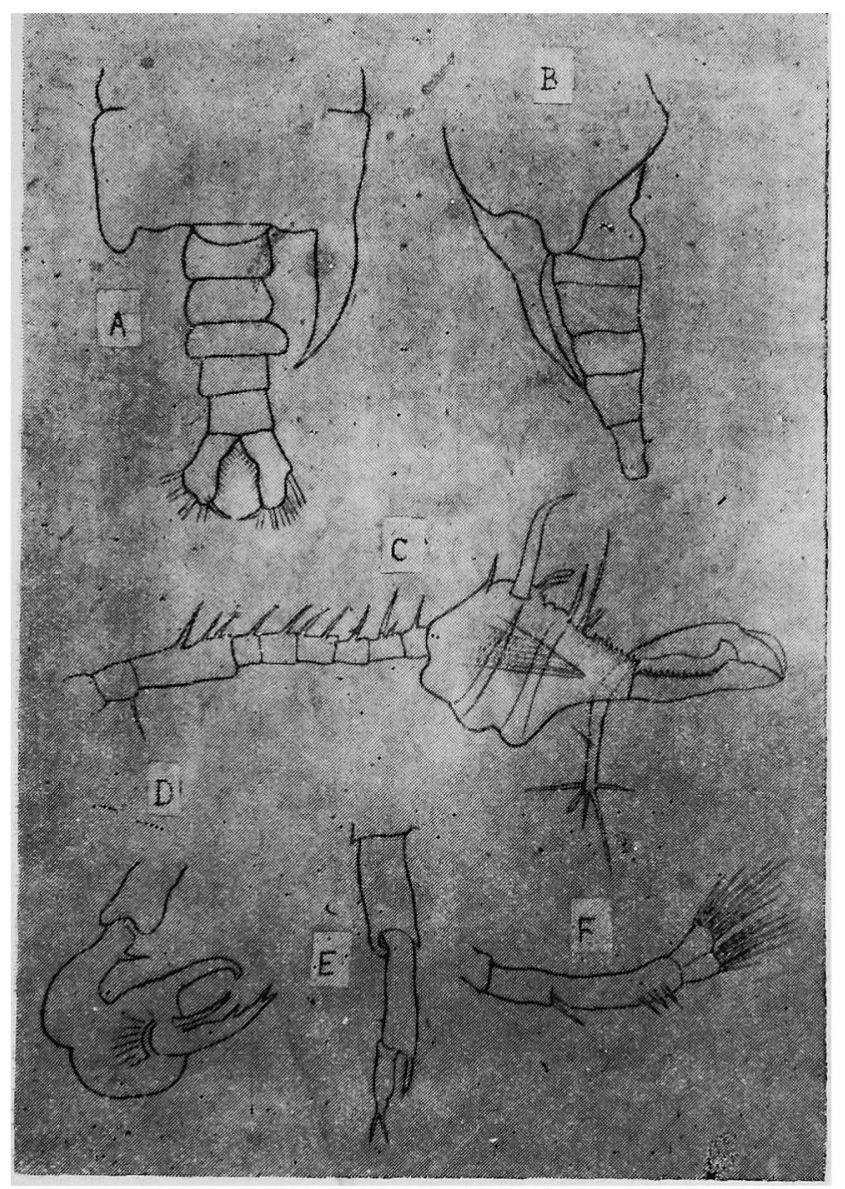

Fig. 1 Pontellapsis pacifica sp. nov.

female. A. head, lateral view, $\times 70$, B. head, ventral view, $\times 90$, C. abdomen, dorsal view, $\times 70$, D. abdomen, ventral view, $\times 70$, E. 5 th pair of feet, $\times 40$, F. left 5 th foot, lateral view, $\times 40$, G. 4 th foot, $\times 50$.

\section{References}

1) T. Mori, 1937. The pelagic copepcda from the neighbouring waters of Japan. p.p. 97-99. pl. $45,46,47$. 


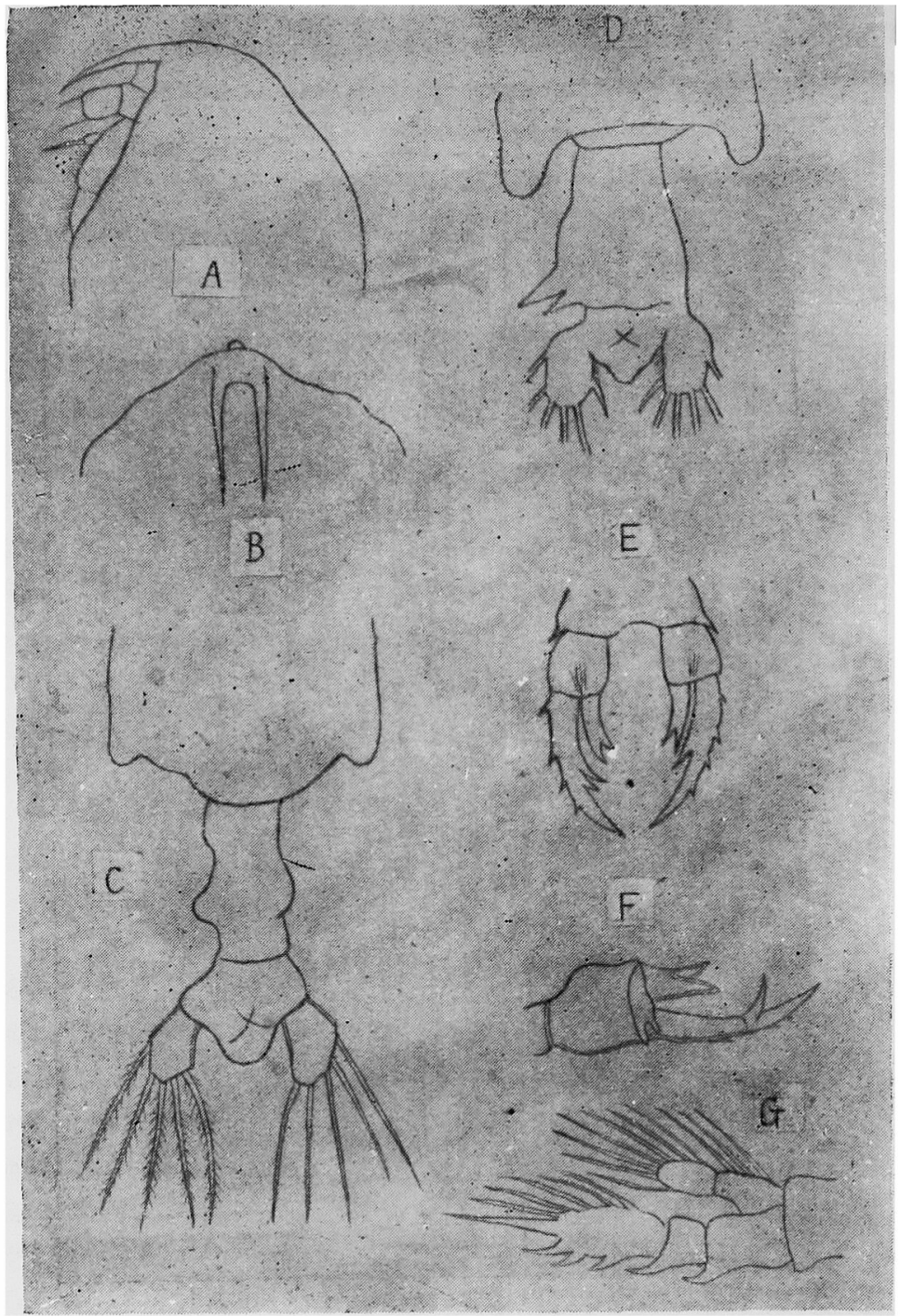

Fig. 2

male. A. aldomen, dorsal view, $\times 50, \mathrm{~B}$, abdomen, iateral view, $\times 50$, C. right lst antenua $\times 60$ D. 5 th right foot, $\times 50$, F, 5 th left foot, $\times 50$, F. exopodite. of 2nd antenna $\times 40$.

2) W. Giesbrecht and O. Fchmfil, 1898. Das Tierreich, Lief. 6. Copepoda, 1, Gyinnoplea, pp. $100-101$.

3) C. B. VIIson, 1951. Contributions to the Biology of the Philippine Archipelago and Adjacent. regions. n. $302-314$, pl. 30, fig. 445462 . 